\title{
International Trade in Genetically Modified Products
}

\author{
E. Kwan Choi
}

Iowa State University and City University of Hong Kong*

March 2009

\begin{abstract}
This paper investigates competition between two markets that sell close substitutes: a traditional product and a genetically modified (GM) product. Tightening an import quota on the GM product raises the prices of both goods and hurts consumers. Two scenarios are considered under free trade: Cournot-Nash equilibrium and Stackelberg equilibrium. A Stackelberg type monopolist produces more, and the competitive traditional firms produce less, than in Cournot-Nash equilibrium. In the long run, an import ban on the GM product does not help competitive producers of the genetically modified organism (GMO)-free products but benefits only the landowners in Europe.

JEL classification code: F1

Keywords: genetically modified products, import ban, landowners

*E. Kwan Choi: Department of Economics, Iowa State University, Ames, IA 50011.

Tel: 515-294-5999, E-mail:kchoi@iastate.edu.
\end{abstract}




\section{International Trade in Genetically Modified Products}

\section{Introduction}

Some regions of Austria, France, Spain, United Kingdom, Greece and Italy declared themselves "the network of GMO-free regions" in November 2003. This declaration may be viewed as a measure to safeguard "genuine and high-quality products.” In the absence of scientific findings on health hazards of genetically modified (GM) products, however, such a ban also may constitute a trade barrier to exclude GM products from the United States and elsewhere.

Consumers cannot readily distinguish between the two products by visual inspection. Despite their apparent resemblance, the GM products often are less costly than GMO-free products (Toolsema, 2008). For example, according to the Director General for Agriculture of the European Union, GM seeds cost more but reduce pesticide costs and have higher yields. ${ }^{1}$ GM crops may be developed to use less water and fewer chemicals in order to conserve resources and protect the environment. According to Mike Duffy (1999), more than half of Iowa farmers cited increased yields as the reason for planting GM soybeans. ${ }^{2}$ Similarly, natural insulin and vaccines are difficult to manufacture in large quantities, while the genetically modified varieties are not.

The purpose of this paper to demonstrate that an import ban on GM products minimizes consumer welfare, and in the long run benefits only landowners, rather than producers of the traditional products. In developing countries, farmers use conventional farming methods to produce traditional or genetically modified organism (GMO)-free products. In contrast, corporate farms in developed economies market GM products. Over 
time, a two-tier price system has developed: a higher price for the traditional, GMO-free products and a lower price for GM products.

Since GM products are cheaper substitutes for the GMO-free products, conventional farmers have an incentive to persuade the government to ban production and imports of GM products. The irony is that landowners, rather than conventional farmers, will benefit from the import bans in the long run. Moreover, import bans may not be in the best interest of consumers, who would be forced to pay higher prices for the traditional products. In the case of organic products, prices are often twice those of conventional products (Clarkson, 2007).

This paper is organized as follows: Section 2 lays out the basic model of two markets producing close substitutes. Section 3 considers impacts on the representative consumer of an import quota on GM products. Section 4 illustrates a Cournot-Nash equilibrium under free trade, while Section 5 shows a Stackelberg equilibrium in which the foreign monopolist behaves strategically. Section 6 demonstrates that only landlords, not producers, benefit from import bans of GM products at the expense of consumers. Section 8 presents the concluding remarks.

\section{Two Markets Producing Close Substitutes}

This section establishes a basic model to investigate trade in GM products between two developed economies: Europe and America. ${ }^{3}$ Consider a representative consumer spending fixed income $I$ on three products, the genuine or traditional product $Y$, the GM

product $X$, and the numéraire $Z$. The traditional product and the numéraire are produced in the Home Country (Europe), while the GM product is imported from the Foreign Country (America). 
The GM product is not a bad, but a good, and marginal utility of the GM product is positive. The GM product serves some, but not all, functions of the traditional product. That is, the GM product is inferior to, and an imperfect substitute for, the traditional product (Toolsema, 2008). This difference in quality between the two products may be factual or perceived. Even if there are no discernible chemical differences, consumers may feel that the GM product is inferior to the traditional product. ${ }^{4}$

Higgins and Rubin (1986) suggest that in some cases consumers may be deceived and think that they are buying genuine goods when they are not. It may be difficult for consumers to discriminate between two goods that functionally are almost identical. Consumers cannot distinguish GM products from GMO-free products by visual inspection. Products can be differentiated only by DNA analysis in laboratories. Thus, they are perfect substitutes in the absence of labels but are “close substitutes” when correct labels identify them as such. Consequently, any analysis of one market is incomplete without examining its impact on the other market.

Consumer welfare is represented by a monotone increasing, quasi-concave utility function $u(X, Y, Z)$. The consumer's problem is to maximize utility $u(X, Y, Z)$, subject to a budget constraint, $P X+p Y+Z=I$, where $p$ and $P$ are the prices of the traditional product and the GM product, respectively. The first order conditions are:

$$
\begin{aligned}
& u_{X}-\lambda P=0, \\
& u_{Y}-\lambda p=0, \\
& u_{Z}-\lambda=0 .
\end{aligned}
$$


where $\lambda$ is the Lagrange multiplier. Demand functions for the three goods are written as $X(P, p, I), Y(P, p, I)$, and $Z(P, p, I)$. Substituting the demand functions into the utility function, the indirect utility function is obatained:

$$
V(P, p, I) \equiv u(X(P, p, I), Y(P, p, I), Z(P, p, I)) .
$$

Prices are endogenous and can be affected by quotas. ${ }^{5}$ The GM products and GMO-free products are difficult to distinguish merely by the naked eye or consumption, and consumers usually rely on product labels to differentiate the two. (Gruere, Carter and Farzin, 2008). Because they are close substitutes with proper labels, the demand for one product is sensitive to any changes in the market for the other.

The GM product requires extensive R\&D, and the GM technology is not easily copied by others. Due to the technological barrier, the producer of the GM product is assumed to be a monopolist. In contrast, the traditional product is produced by many firms. Assume that there are $n$ identical producers of the traditional product in Europe. Let $y$ denote the output of the representative producer, and $Y=n y$ be the total output of the traditional product by European firms. The inverse demand for the GMO-free product in Europe is given by:

$$
p=a-b Y-g X,
$$

where $a, b$, and $g$, are positive constants, and $p$ and $X$ are the price and quantity of the GM good produced by the monopolist in America. To comply with government regulations, the GM products are labeled as such to help consumers identify the two products. Since the two products are close but not perfect substitutes $(g<b)$, the presence of the GM product decreases the demand for the GMO-free product $(g>0)$. 
The inverse demand function for the GM product is given by:

$$
P=A-B X-G Y \text {, }
$$

where $P$ is the price of the GM product and $A, B$ and $G$ are a positive constants. Since the traditional product and the GM products are close substitutes, the price of a product is inversely related, not only to its own quantity, but also to the quantity of the other product $(G>0) .{ }^{6}$ Since they are not perfect substitutes, the slopes of cross-demand curves are less than those of own demand curves, i.e., $g<b$ and $G<B$. Moreover, due to close substitutability between the two goods, the single producer has weak monopoly power. ${ }^{7}$

Solving the system of two equations in (3) and (4), we obtain:

$$
\begin{aligned}
& X=\frac{b(A-P)-G(a-p)}{\Delta}, \\
& Y=\frac{B(a-p)-g(A-P)}{\Delta},
\end{aligned}
$$

where $\Delta \equiv b B-g G>0$ by assumption. Note that $g>0$ and $G>0$ imply that cross demand curves are positively sloped; i.e., an increase in the price of one good increases the demand for the other product.

\section{Effects of Import Qutoas and Ban}

Let $X^{*}$ denote the level of the GM product imported from America under free trade. Suppose Europe imposes an import quota $Q, Q<X^{*}$, on the GM product. Demands for the two goods are now written:

$$
p=a-b Y-g Q
$$




$$
P=A-B Q-G Y
$$

Differentiating (5) and (6) with respect to $Q$ :

$$
\begin{aligned}
& \frac{\partial p}{\partial Q}=-g<0, \\
& \frac{\partial P}{\partial Q}=-B<0 .
\end{aligned}
$$

Therefore, tightening an import quota raises the prices of both goods. We assume that as the import quota on $X$ is tightened, its price rises more than that of its substitutes ( $B>g$ ).

Figure 1 illustrates the impact of an import quota on the GM product market. In the absence of an import quota, Europe imports $X^{*}$, and consumer surplus is the area of $c d^{\prime} e^{\prime}$. The exporter in America enjoys producer surplus of $d^{\prime} e^{\prime} f$. When an import quota $Q$ is imposed, consumer surplus shrinks to the area of $c d e$, while producer surplus of the exporter increases to the trapezoidal area $d e f h$. As a special case, when imports are banned altogether, consumer surplus and producer surplus vanish. 


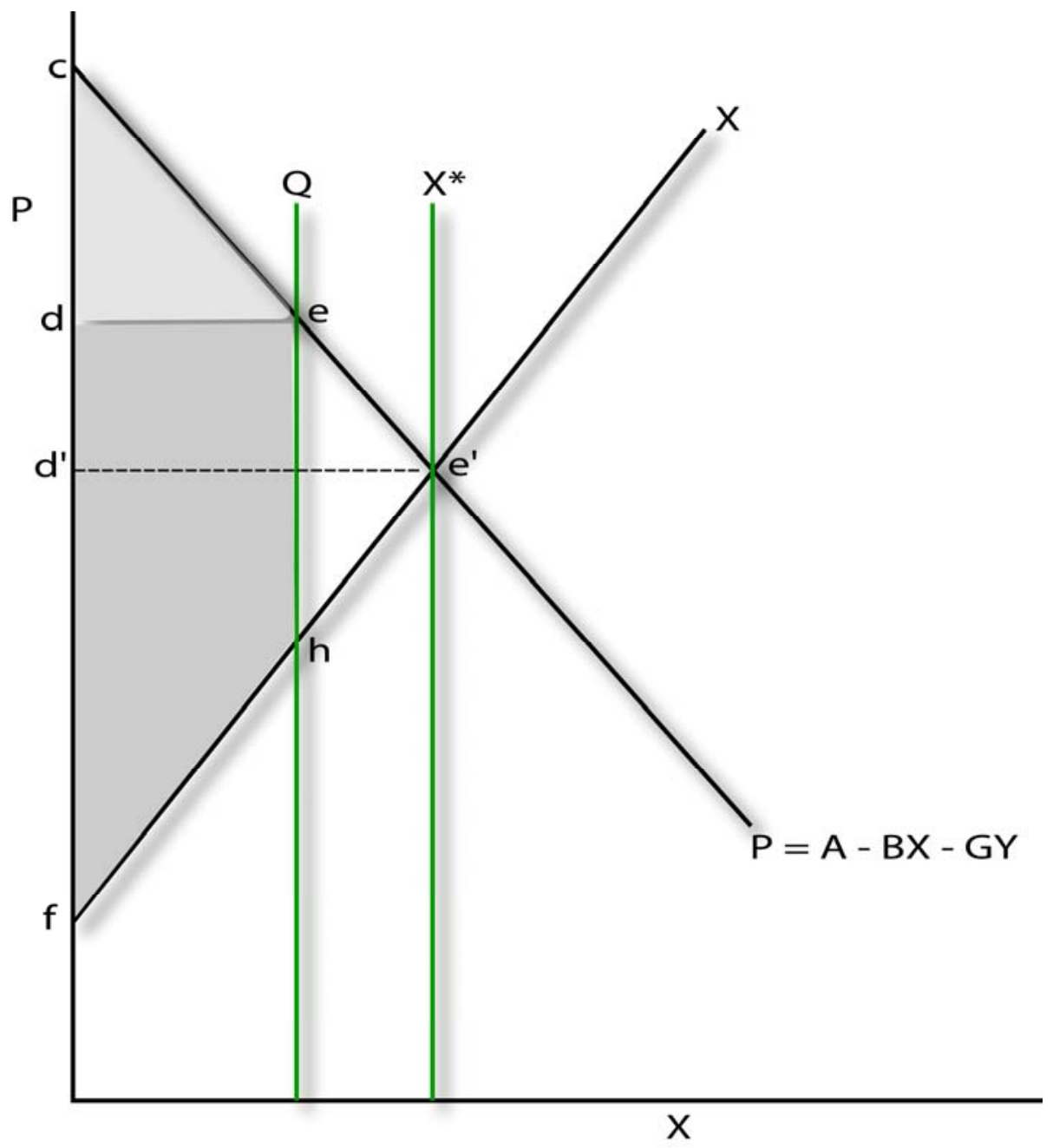

Figure 1. Effect of an Import Quota

Next, consider the impact of a quota on the market for the traditional product. In the absence of an import quota, consumer demand for the traditional product is represented by the inverse demand function, $p=a-b Y-g X$. Consumer surplus from the traditional product is represented by $c^{\prime} d{ }^{\prime} e^{\prime}$, whereas domestic producer surplus is $d^{\prime} e^{\prime} f$. 


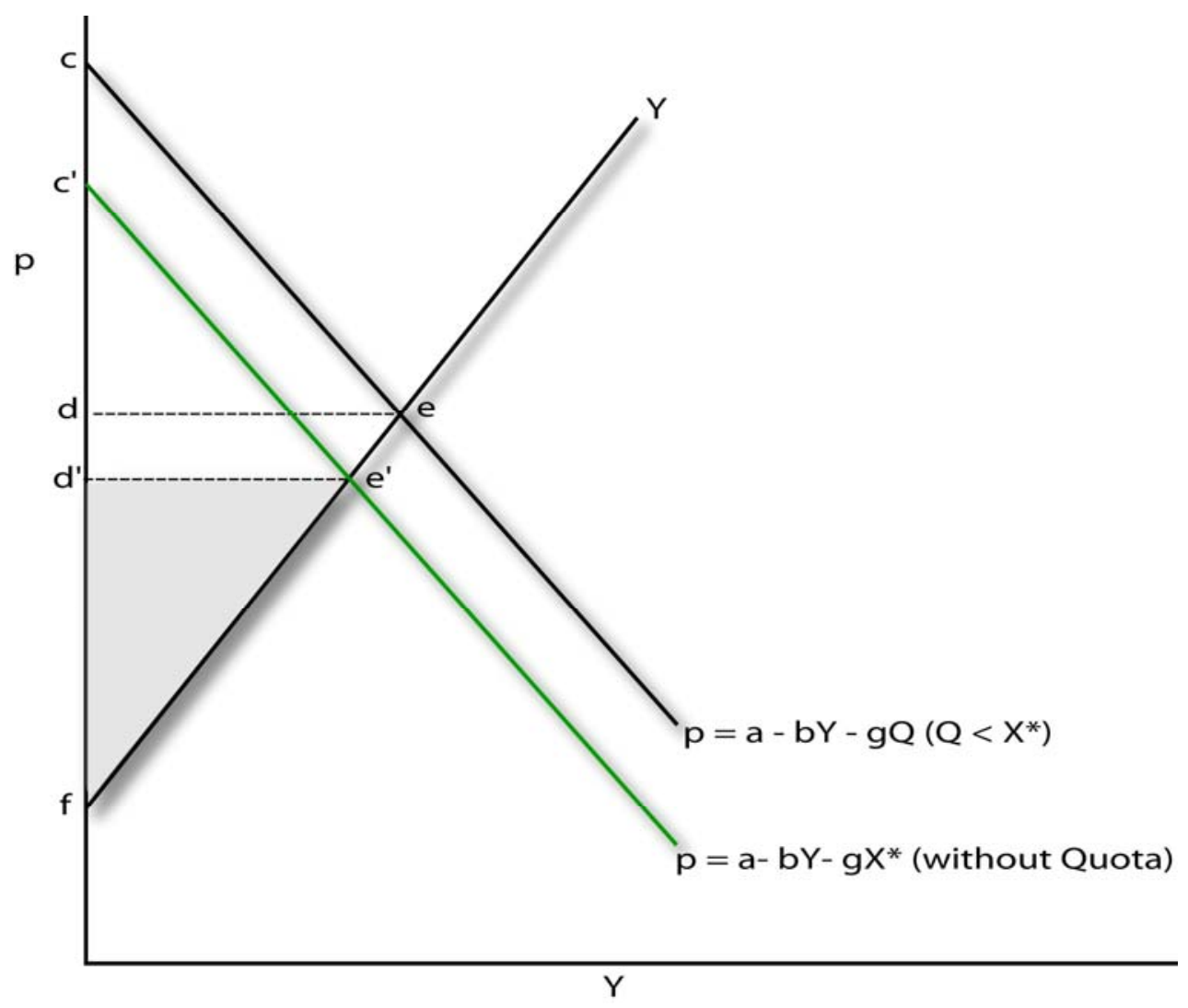

Figure 2. Quota and Demand for the Traditional Product

When an import quota $Q$ is imposed, the demand curve for the traditional product shifts upward to $p=a-b Y-g Q$. Since the quota raises the domestic price of the traditional product, the producer surplus definitely increases.

Such a shift in demand may increase or decrease consumer surplus from the traditional product. In the case of a parallel shift, consumer surplus rises when a quota is imposed. However, consumer surplus from either the traditional product or the GM product may not be a good indicator of the welfare change. Since any restriction on consumption reduces consumers' feasible choice set, consumer welfare will decline as a result of an import quota.

Using the inverse demand functions in (5) and (6), the indirect utility is written: 


$$
V(P, p, I)=V(A-B Q-G Y, a-b Y-g Q, I)
$$

To assess welfare impacts of an import tariff, the indirect utility in (9) can be differentiated with respect to $Q$. Use of Roy's identities, $V_{P} \equiv-V_{I} X$ and $V_{p}=-V_{I} Y$, results in:

$$
\frac{d V}{d Q}=\left[-V_{I} Q\left(-B-G \frac{\partial Y}{\partial Q}\right)\right]+\left[-V_{I} Y\left(-g-b \frac{\partial Y}{\partial Q}\right)\right]
$$

where the first bracketed term is the direct effect of the quota on utility through a change in the price of the GM product and the second term is the indirect effect through a change in the price of the conventional product. Note that $\partial Y / \partial Q$ is the slope of the competitive firms' reaction curve $r(X)$ to be derived shortly. Recall that the own-price effects are greater than the cross-price effects $(b>g, B>G)$. Using $\partial Y / \partial Q=-g / b$ and rearranging terms, we have

$$
\frac{d V}{d Q}=V_{I} Q \frac{(b B-g G)}{b}>0
$$

When evaluated at $Q=0, \frac{d V}{d Q}$ reduces to zero. Thus, indirect utility reaches a minimum when an import ban is imposed. As the import quota is relaxed, indirect utility rises. However, the quota cannot be raised beyond the amount the exporter is willing to supply. Thus, for all feasible values of quota below a maximum level , $X^{\max }$, indirect utility increases as the quota is relaxed. Intuitively, an increase in quota lowers the price of the GM product. Since the two goods are close substitutes, the increase in quota on GM product also lowers the price of the conventional product. Recall that indirect utility is decreasing in the price of each good. Thus, indirect utility decreases as the quota is tightened and the price of the imported GM product rises, as shown in Figure 3. 
Proposition 1: Assume that the traditional product is produced in Europe and the GM product is imported from America. Tightening an import quota on GM products decreases consumer welfare, i.e., $\frac{d V(P, p, I)}{d Q}>0$, and an import ban hurts consumers.

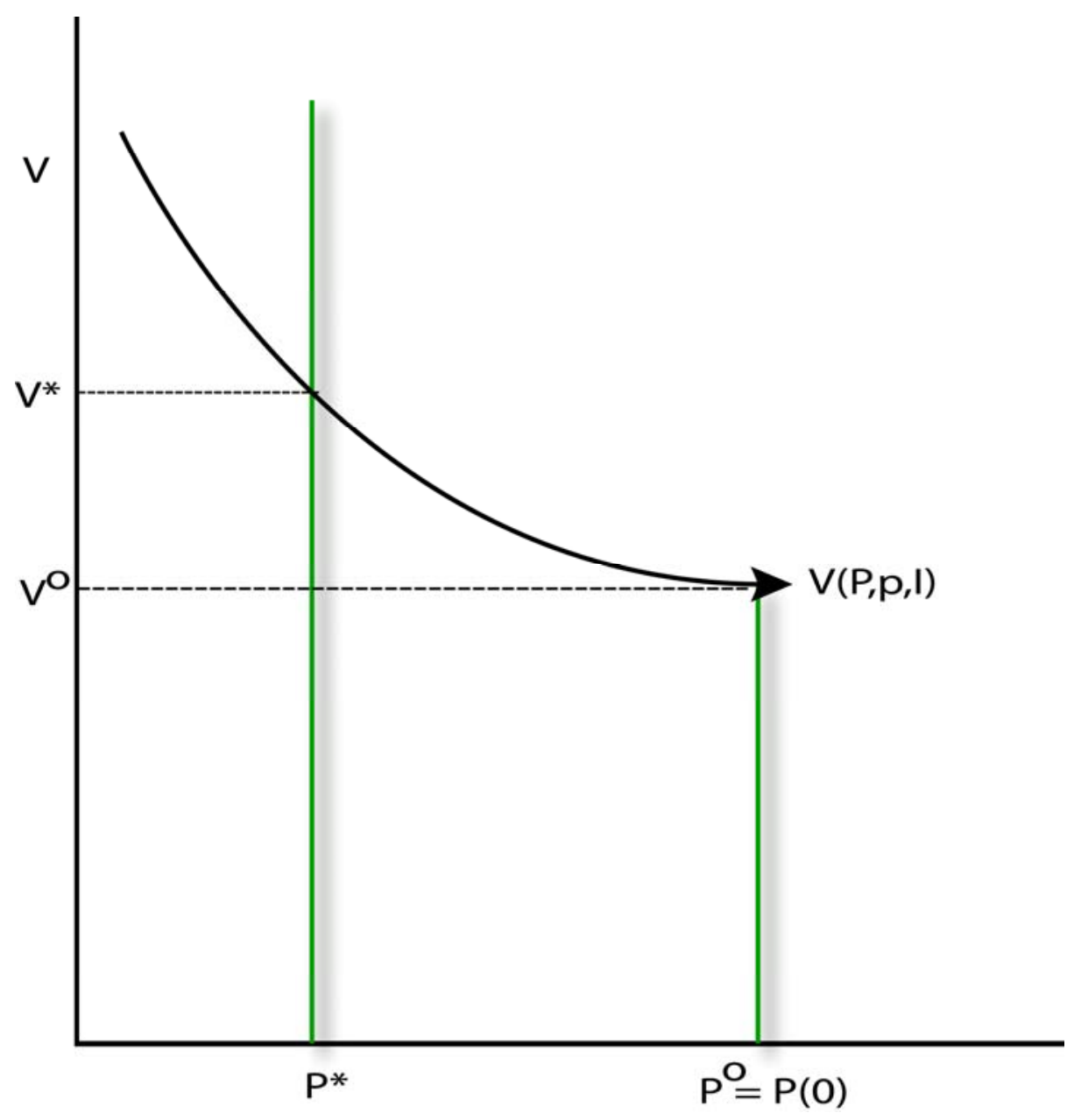

Figure 3. Welfare Effects of Import Quotas

\section{Cournot-Nash Equilibrium of Two Markets under Free Trade}

We now consider a Cournot-Nash equilibrium in the two markets in the absence of government intervention. A Cournot-Nash equilibrium occurs between two markets under free trade when each industry assumes that the output of the other industry is fixed. ${ }^{8}$ 
Although the supply of the GM product decreases the demand for the traditional product, each competitive firm is a price taker and takes the output of the other industry $X$ as given. Also, the monopolist of the GM product assumes that the output $X$ in the other market is given.

The traditional sector produces $Y=f(T, L)$ using two inputs, land $(T)$ and labor $(L)$, and the industry's production costs are given by $c=w L+s T$, where $w$ is wage and $s$ is land rental in Europe. Let $c(Y, w, s)$ denote the minimum cost of producing $Y=f(T, L)$. Similarly, the monopolist produces $X=F\left(T^{*}, L^{*}\right)$ using land $\left(T^{*}\right)$ and labor $\left(L^{*}\right)$ inputs in America. Let $C\left(X, w^{*}, s^{*}\right)$ denote the minimum cost of producing $X=F\left(T^{*}, L^{*}\right)$. The aggregate profit of traditional producers is:

$$
\pi=(a-b Y-g X) Y-c(Y),
$$

where $c(Y)=n c(y)$ is the aggregate production cost of $n$ firms and factor prices $(w, s)$ are suppressed for simplicity. Since the traditional producers are price takers,

$$
\frac{\partial \pi}{\partial Y} \equiv a-b Y-g X-c^{\prime}=0,
$$

which defines the competitive industry's best response, $Y=r(X)$ to the monopolist's output $X$. The best response curve is denoted by $r r$ in Figure 4. Differentiating (13), the slope of the competitive industry's best response curve is:

$$
\left.r^{\prime}(X) \equiv \frac{d Y}{d X}\right|_{r}=-\frac{\pi_{Y X}}{\pi_{Y Y}}=-\frac{g}{b}<0,
$$

i.e., the competitive industry decreases output as the monopolist expands. 
Next, consider the production decision of the GM product. The monopolist's profit is

$$
\Pi=(A-B X-G Y) X-C(X),
$$

where $C(X)$ is the production cost and factor prices $\left(w^{*}, s^{*}\right)$ are suppressed. The first order condition is

$$
\frac{\partial \Pi}{\partial X} \equiv A-2 B X-G Y-C^{\prime}=0,
$$

where $M_{X}=P-B X=(A-2 B X-G Y)$ is marginal revenue. The monopolist's marginal revenue, as well as the demand curve, are adversely affected by the output of competitive firms.

While the monopolist is a price maker in its market, its output decision is based on the output of the traditional industry that produces a close substitute. Equation (15) defines the monopolist's best response, $X=R(Y)$, to the competitive industry's aggregate output. The best response curve of the monopolist is denoted by $R R$ in Figure 4. Differentiating (15), the slope of the monopolist's best response curve is:

$$
\left.R^{\prime}(Y) \equiv \frac{d X}{d Y}\right|_{R}=-\frac{\Pi_{X Y}}{\Pi_{X X}}=-\frac{G}{2 B}<0
$$

Thus, the monopolist's output decreases as the competitive industry expands. Let $\left(X^{o}, Y^{o}\right)$ denote the pair of outputs of the monopolist and the competitive firms in Cournot-Nash equilibrium. Combining the behavioral equations (15) and (13), we obtain a Cournot-Nash equilibrium: 


$$
\begin{gathered}
X^{o}=\frac{b A^{*}-G a^{*}}{2 b B-g G}, \\
Y^{o}=\frac{2 B a^{*}-g A^{*}}{2 b B-g G},
\end{gathered}
$$

where $A^{*}=A-C^{\prime}>0, a^{*}=a-c^{\prime}>0$, and $2 b B-g G=b B+\Delta>0$ to ensure positive outputs. The best response function of the monopolist is steeper than that of the competitive industry, as shown in Figure $4 .^{9}$

\section{Stackelberg Equlibrium}

An asymmetric pairing of competitive firms and a single monopolist suggests that the monopolist can behave strategically. Due to the difficulty of coordinating outputs among a large number of firms, however, competitive firms cannot display strategic behaviors. Thus, the competitive producers are assumed to be price takers and behave as if monopoly output $Y$ is given.

We now consider competition between two markets when the monopolist behaves strategically. Due to intermarket dependence, the monopolist’s revenue, $M R_{X} \equiv A-2 B X-G Y$, depends on the output of the GMO-free product. Specifically, an increase in the industry output of the GMO-free product shrinks the monopolist's marginal revenue. Moreover, the monopolist observes the best response function $Y=r(X)$ of the competitive producers. When the best response function, $r(X)$, is taken into account, the monopolist's profit function reduces to:

$$
\Pi=(A-B X-G r(X)) X-C(X) .
$$


The first order condition is:

$$
\frac{\partial \Pi}{\partial X} \equiv-\left(B+G r^{\prime}\right) X+(A-B X-G r(X))-C^{\prime}=0 .
$$

For a naïve monopolist in Cournot-Nash equilibrium,

$-B X+(A-B X-G r(X))-C^{\prime}=0$. Thus, when evaluated at the naïve monopolist's output, $X^{o}$, the left-hand side is $-G r^{\prime}(X)=g G / b>0$. It follows that the Stackelberg-type monopolist produces more than the naïve monopolist. Let $\left(X^{S}, Y^{S}\right)$ denote the outputs of the two industries in a Stackelberg equilibrium when the monopolist becomes a Stackelberg leader and competitive firms are price takers.

Proposition 2: Consider two markets with a single monopolist of the GM product in America and many producers of the GMO-free products in Europe. Under free trade, a Stackelberg-type monopolist produces more, and the competitive traditional firms produce less, than in Cournot-Nash equilibrium, i.e., $X^{S}>X^{o}$ and $Y^{S}<Y^{o}$.

In Figure 4, Cournot-Nash equilibrium and Stackelberg equilibrium are denoted by $\left(X^{o}, Y^{o}\right)$ and $\left(X^{S}, Y^{S}\right)$, respectively. A Stackelberg-type monopolist recognizes its influence on the output of the competitive firms. Together with the competitive producers, the monopolist chooses point $\left(X^{s}, Y^{s}\right)$, while the Nash-type monopolist and competitive firms jointly choose $\left(X^{o}, Y^{o}\right)$. 


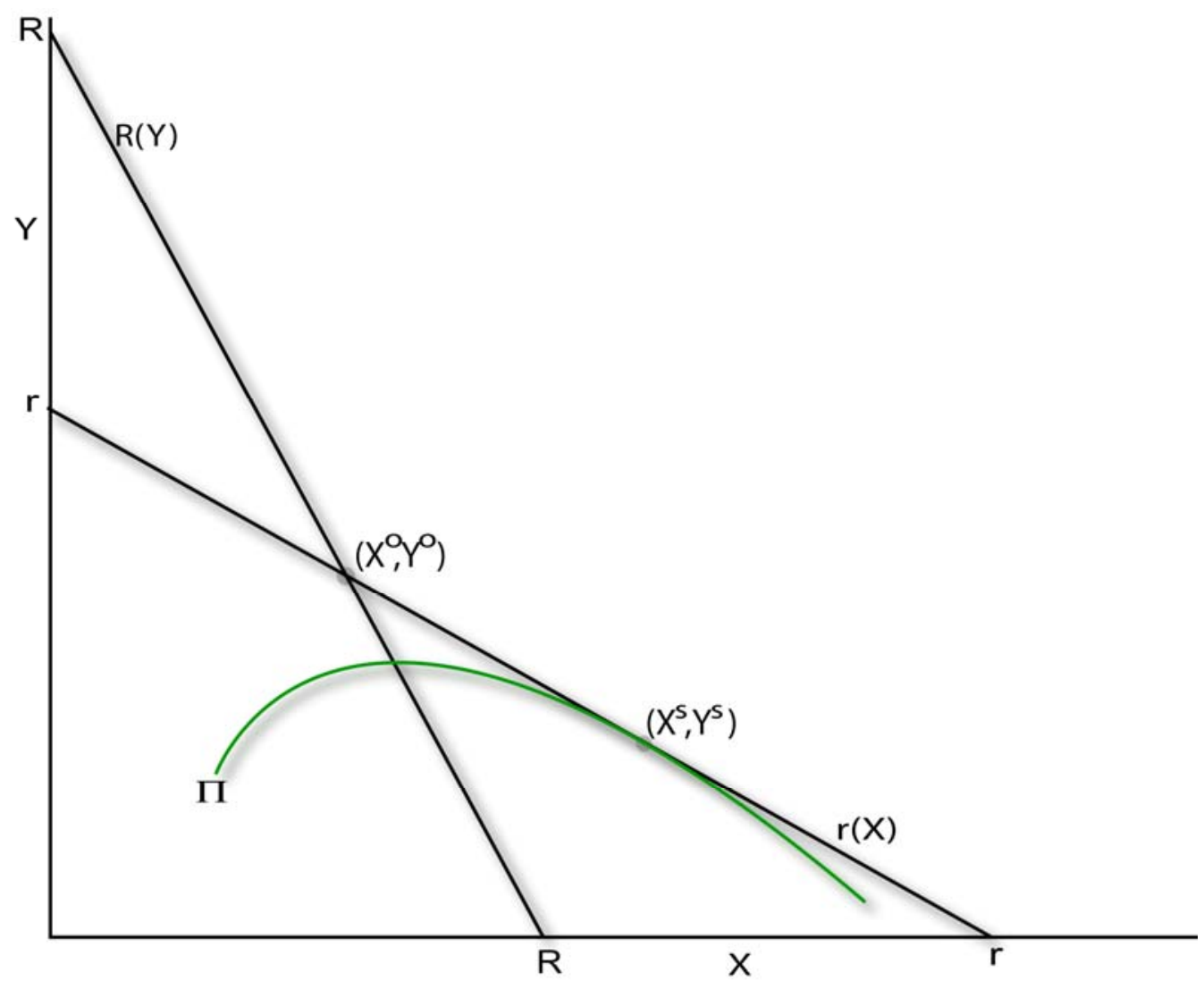

Figure 4. Cournot-Nash Equilibrium and Stackelberg Equilibrium

Consumer welfare under three scenarios also can be compared in Figure 5. When an import ban is imposed ( $Q=0)$, the traditional industry chooses point $a$ on its best response curve $r(X)$, and consumer welfare is represented by the indifference curve $\mathrm{U}^{\mathrm{Ban}}$. Under free trade, a Cournot-Nash equilibrium occurs at $\left(X^{o}, Y^{o}\right)$, where the utility level rises to $\mathrm{U}^{*}$. Since the quantity of the numéraire is not held constant, a higher indifference curve does not necessarily indicate a higher utility level. However, equation (10) indicates that welfare increases with $\mathrm{Q}$, and hence there is no need to restrict the output of the Stackelberg-type monopolist. Although indirect utility rises with $\mathrm{Q}$, it has an upper bound of $X^{S}$, which is the maximum amount of $X$ the monopolist is willing to produce for the European market. 
Intuitively, increased imports of the GM product lowers the prices of both goods and hence, benefits consumers.



Figure 5. Consumer Welfare under Three Scenarios

\section{Beneficiaries of Import Bans}

Import bans on GM products often are justified as a means of protecting European consumers. In the absence of scientific evidence, import bans may become only a trade barrier to exclude imports from other countries. Import bans also receive popular political support because supposedly they aid domestic producers of traditional products. But equations (7) and (8) show that an import ban actually raises the domestic price of the 
traditional product. Thus, producers of GMO-free goods may erroneously conclude that they would benefit from such import bans on GM products.

It should be noted that traditional products are produced in competitive markets and entry is free. Assume that initially the markets are in long-run Cournot-Nash equilibrium and that domestic producers earn zero profits. Consider now the long-run impacts of an import ban on the GM products. In the short run, such a ban raises the price of the GMO-free product and profits of traditional producers. However, as more farmers enter the industry, the land rent is bid. Entry of farmers into the traditional sector continues until profits of traditional producers are reduced to zero at new rent.

Thus, long run profits are again zero at the new equilibrium rent, which satisfies the zero profit constraint under a quota:

$$
(a-b Y-g Q) Y-w L-s T=0 .
$$

Differentiating (20) with respect to $Q$ yields:

$$
\frac{\partial s}{\partial Q}=-\frac{g Y}{T}<0 .
$$

Thus, relaxing an import quota lowers land rent. This implies that an import ban on the GM product raises land rent.

Since long run profits cannot be affected by an import ban on the GM product, a socially optimum solution is one that maximizes consumer welfare. Contrary to widespread belief, import bans on GM products do not help producers in the long run, and hurt consumers instead. 
Proposition 3. Assume that land inputs used in the traditional sector in Europe and the GM sector in America are fixed. Then in the long run, an import ban on the GM product does not benefit the traditional producers but only benefits landowners in Europe.

\section{Concluding Remarks}

This paper considered competition between two markets selling two close substitutes. Since consumers cannot differentiate the two products by visual inspection or consumption, the two products are perfect substitutes in the absence of labels but become imperfect substitutes when correct labels distinguish them. When consumers are properly informed and products are correctly labeled, they can make best consumption decisions.

The majority of GM products are produced by high-income countries and sold in both the developed and developing countries. Citing potential health risks, European countries have objected to imports of GM products. This paper shows that import quotas on GM products raise the price of the traditional product and minimize consumer welfare, and that in the long run only landowners, and not producers of the traditional product, benefit from import bans.

An important policy implication of the analysis is that in the absence of concrete scientific evidences, EU's current ban on GM products enriches landowners, contrary to their professed intent. In the case of organic and nonorganic products, organic prices are two to three times higher than conventional prices (Clarkson, 2007). European consumers may pay a similar premium for conventional products because of the import ban on GM products.

The analysis is based on the assumption that all products are properly labeled and no counterfeit trading occurs. When there is a significant price difference, however, firms have 
an incentive to slip unlabled GM products into the traditional market and pass them off as GMO-free products. More research is needed on regulating counterfeit trading between the two markets.

\section{REFERENCES}

Choi, E. K. (2007). “North-South Trade and Income Inequality,” International Review of Economics and Finance 16, 347-356.

Choi, E. K. (2008). “Factor Growth and Equalized Factor Prices,” International Review of Economics and Finance 17, 517-28.

Clarkson, L. (2007). “Statement of Lynn Clarkson, President of Clarkson Grain Co., Inc.,” a statement before The US House of Representatives’ Agriculture Committee’s Subcommittee on Horticulture and Organic Agriculture, April 18, 2007.

http://agriculture.house.gov/testimony/110/h70418/LClarkson.doc. Accessed February 14, 2009.

Directorate-General for Agriculture, European Commission (2007). “Economic Impacts of Genetically Modified Crops on the Agri-food Sector,” Chapter 3, http://ec.europa.eu/agriculture/publi/gmo/ch3.htm, Accessed on March 31, 2007.

Duffy, M. (1999), “Is GMO or Non-GMO More Profitable — A Look at 1998,” $A g D M$ newsletter.

Gruere, G. P., Carter, C. and Farzin, H. (2008). "What Labelling Policy for Consumer Choice? The Case of Genertically Modified Food in Canada and Europe,” Canadian Journal of Economics 41,1472-97.

Higgins, R. and Rubin, P. (1986). “Counterfeit Goods,” Journal of Law and Economics 29, 211-30. 
Long, N. V. (2005). “Outsourcing and Technology Spillovers,” International Review of Economics and Finance 14, 297-304.

Toolsema, L. (2008). “Competition with Mandatory Labeling of Genetically Modified Products,” Journal of Institutional and Theoretical Economics 164, 429-48.

\section{Acknowledgment}

I am indebted to the seminar participants at The Conference for the Chair of the Americas, University of Paris-I Pantheon-Sorbonne, March 2009. The usual caveats apply.

\section{ENDNOTES}

${ }^{1}$ Similarly, synthetic diamonds are molecularly identical to naturally occurring diamonds, but can be made more cheaply. Likewise, the cost of copying counterfeit DVDs is identical to that of genuine DVDs, but only the original producer pays the actual movie production cost.

${ }^{2}$ Toolsema (2008) also assumes GM products are less costly. Duffy (1999) reported that farmers who used GMO varieties experienced significant savings in herbicide costs, spending nearly 30 percent less than farmers who grew non-GMO soybeans. Farmers using GMOs held a cost advantage in all aspects of weed management, but actual yields were lower. As a result, there was little difference in unit production cost.

${ }^{3}$ The analysis can be extended to trade in GM products between developing and developed economies. See Choi (2007), for instance, for a North-South model that considers income inequality. 
${ }^{4}$ Similarly, in music CDs, DVDs and computer software CDs, information is digitized and digital copies are functionally identical to the originals. Nevertheless, due to heavy advertising of brand name products, consumers may view the copies as imperfect substitutes.

${ }^{5}$ A similar indirect utility is used in Choi (2008), where income is endogenous.

${ }^{6}$ If the two goods were perfect substitutes, then there would be only one price, $P=A-B(X+Y)$ and $G=B=g=b$.

${ }^{7}$ The monopolist may have its own market in America, but that market is ignored in this analysis.

${ }^{8}$ Long (2005) also assumes imperfect substitutability and considers a Nash equilibrium.

${ }^{9}$ The slope of the monopolist's best response function in $(X, Y)$ space is $-2 B$ / $G$ and that of the competitive firm is $g / b$. Hence, $-(2 B b+g G) / b G<0$. 
Iowa State University does not discriminate on the basis of race, color, age, religion, national origin, sexual orientation, gender identity, sex, marital status, disability, or status as a U.S. veteran. Inquiries can be directed to the Director of Equal Opportunity and Diversity, 3680 Beardshear Hall, (515) 294-7612. 